\title{
Exploring the Export Strategy of Chinese Film and TV Drama in Value Chain and Digital Technology
}

\author{
Hongzhe Kang ${ }^{1,2}$, Megat Al Imran Yasin²*, Mohd Nizam Osman², Lay Hoon Ang ${ }^{3}$, Mengyu Li \\ ${ }^{1}$ School of New Media Art, Xi'an Polytechnic University, 710048 Xi'an, China \\ ${ }^{2}$ Department of Communication, Universiti Putra Malaysia, 43400 Serdang, Malaysia \\ ${ }^{3}$ Department of Foreign Languages, Universiti Putra Malaysia, 43400 Serdang, Malaysia
}

\begin{abstract}
The spiritual and cultural needs of residents have been a growing trend with the living standards improving in China. As an essential medium to reflect the social status, film and TV drama need to satisfy the spiritual and cultural needs of residents as well as spread positive energy to society. The Silk Road International Film Festival was founded in 2014 under the Belt and Road Initiative, which created more opportunities for the export of Chinese film and TV drama. Although the value chain and digital technology can support the export of Chinese film and TV drama, some problems still exist. This paper analyzes the value chain status of film and TV drama and the digital technology of visual effects. Moreover, this paper describes the export status of Chinese film and TV drama and puts forward some suggestions.
\end{abstract}

\section{Introduction}

The film and television industry is a sunrise industry in this century which has received wide focus in the world. With advances in digital technology, the film and television industry has been significant development and has formed a well-established global value chain [1]. The value chain is multi-level and multi-angle research from macro to micro. It is based on the law of value transfer of input-output and spatial distribution. In economic globalization, industrial upgrading is constrained by the level of development and the international division of labor in the economy and society. Therefore, the upgrading of the film and television industry should not only follow the natural sequence of industrial evolution but also through the integration of global industries [2]. Visual effects is a method of post-processing images by using digital technology, which can bring visual enjoyment to the audience. Currently, visual effects has been used in many scenes, such as the space world, ancient history, natural disasters and others. The filmmakers can create virtual scenes through computer software so that the audience will have a real virtual illusion. With the development of digital technology, the audience can experience increasing real sense with film and TV drama offering realistic visual effects [3].

\section{Related concepts}

\subsection{The value chain of the film and television industry}

The film and television industry is one of the most dynamic industries in the value chain of the cultural industry. The core characteristics of the value chain are self-regulation and extension to related industries. Audience needs are the foundation of value chain construction of the film and television industry, which will create economic and social value. In value-driven force, film and television industry will experience relevant industry value chain extension of the value creation process [4]. The construction of the film and television industry value chain presents self-regulation, including production, marketing, distribution and cinema, which will constitute the core link of the value chain. The value chain of derivative industries has been extended to publishing, animation, game, network, toy, theme park, tourism, clothing and other industries. Through two-way docking and interactive transmission, it will create an ever-expanding marginal value [5]. The value chain of the film and television industry is shown in Figure 1. 


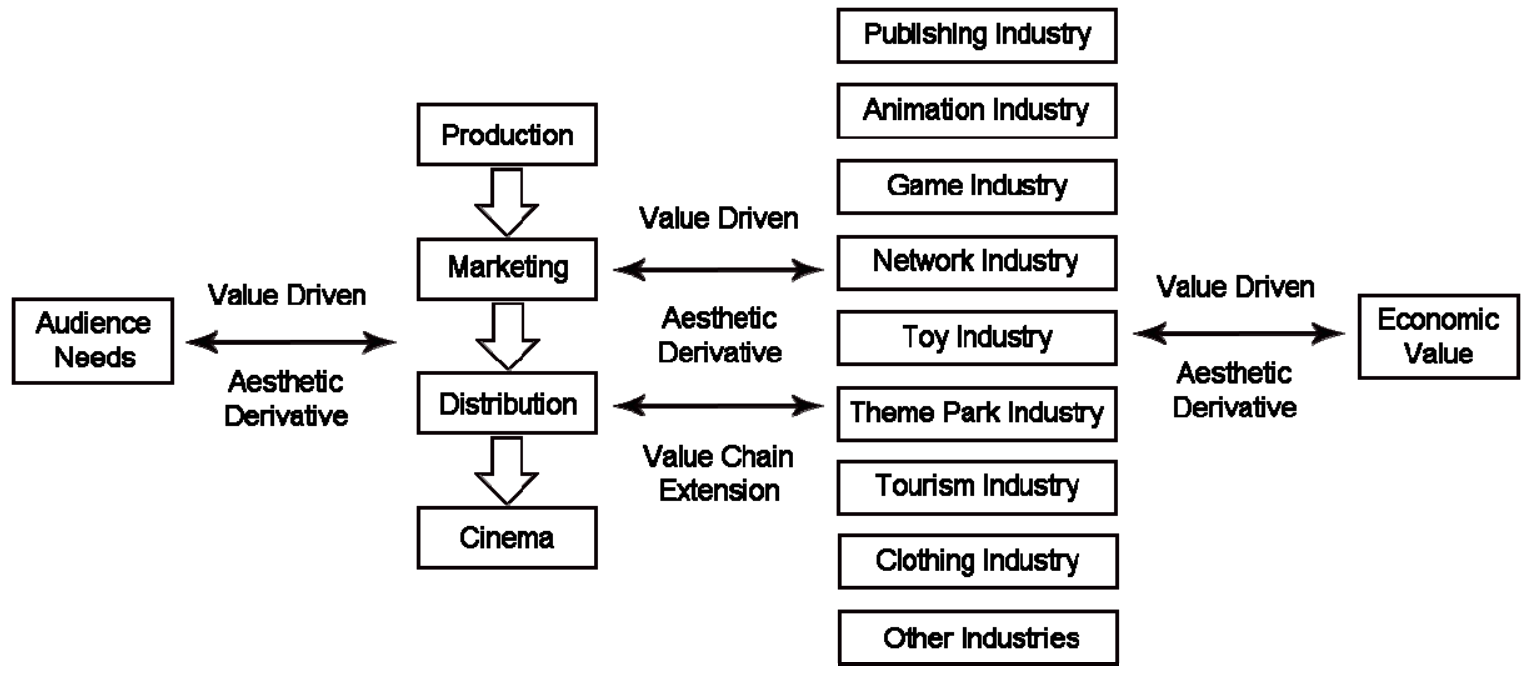

Figure 1. The value chain of the film and television industry.

\subsection{The digital technology of visual effects}

Visual effects design is used to process the modeling of characters and scenes outside the lens. Virtual characters and scenes for creating image effects are generated by computer graphics techniques, which that visual experiences cannot provide. Virtual scenes can simulate artificial scenes beyond real scenes, thus creating characters and environments that are not in real life [6]. Through virtual scenes, filmmakers can expand the real world and sensory experience. The well-known visual effects design software in the industry includes $3 \mathrm{ds}$ Max, Maya, Softimage XSI, Cinema 4D, Houdini and RealFlow. The combination of computer synthesis technology and 3D technology enables visual effects to get rid of the constraints of low efficiency and low-quality image, and dramatically reduces the threshold requirements for materials. Through layers, tracks and nodes to composite images, the virtual scene becomes more sophisticated [7]. This paper analyzes the digital technology of visual effects, as shown in Figure 2.

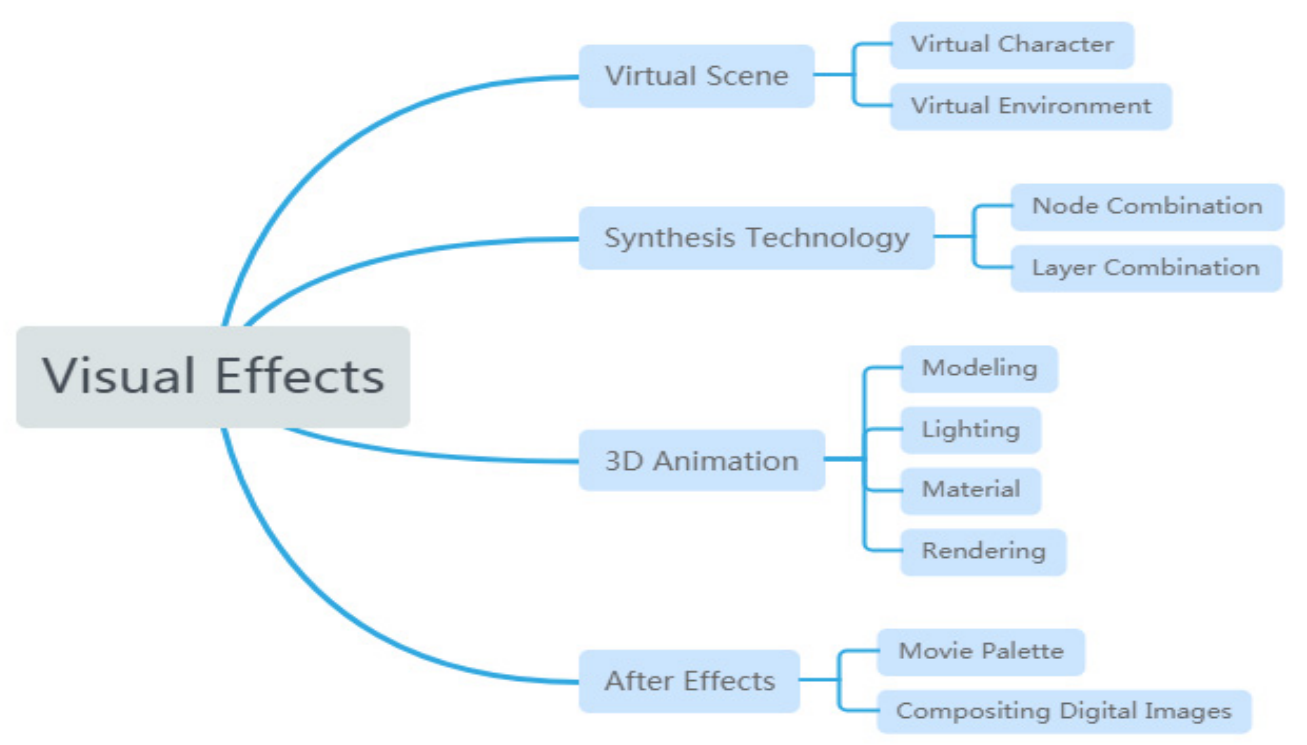

Figure 2. The digital technology of visual effects. 


\section{The export status of Chinese film and TV drama}

\subsection{The number of Chinese film and TV drama exports}

From 2007 to 2015, the growth rate of Chinese film and TV drama exports showed an overall upward trend. The number of annual exports has increased from 402 films in 2007 to 686 films in 2015. A total of 745 films were exported in 2012, the largest number of films exported in recent years. After 2013, the growth rate of Chinese film exports has increased steadily. It is found that the Belt and Road Initiatives has greatly promoted the number of Chinese film and TV drama exports, as shown in Figure 3.

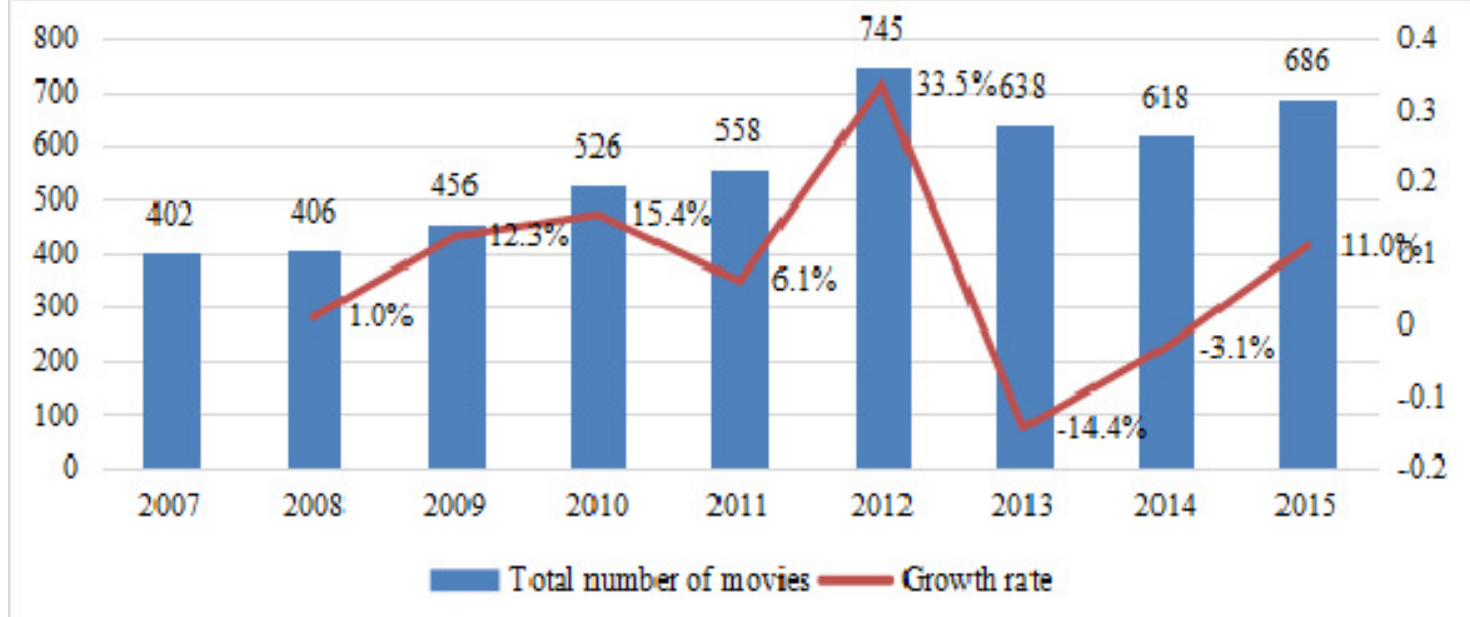

Figure 3. The number of Chinese film and TV drama exports.

\subsection{Comparison of supply and demand index}

The supply and demand index is a qualitative index reflecting the relationship between supply and demand in the market. Since 2008, the supply and demand index of Chinese film and TV drama has been decreasing year by year. With the improvement of living standards, the audience's spiritual and cultural needs for film and TV drama are also increasing. Since 2013, the Chinese film and TV drama supply and demand index is lower than North America and Chinese film and television market is increasingly competitive, as shown in Figure 4.

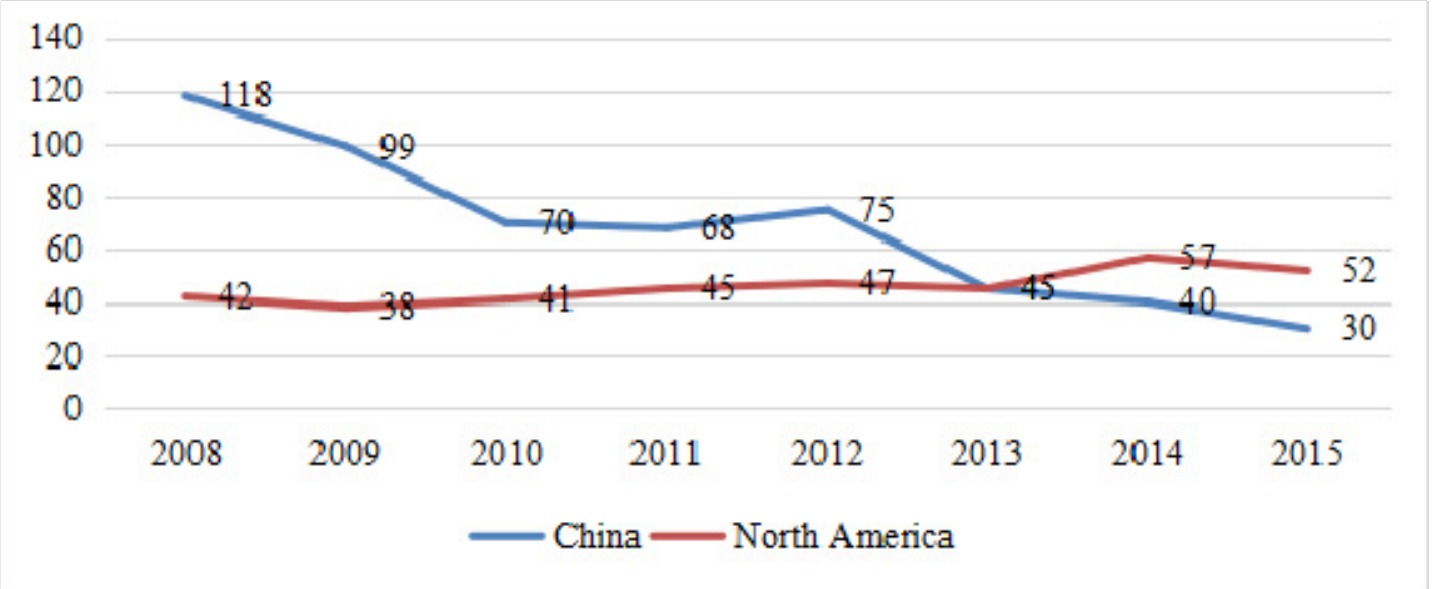

Figure 4. Comparison of supply and demand index between China and North America.

\section{Chinese film and TV drama export strategy}

\subsection{Establish an export support fund}

There are many problems in the financing of the film and television industry, such as small scale and narrow channels. It has hindered the production and export of Chinese film and TV drama. Therefore, the government could increase investment and financing. Some measures can be taken to promote the development of the film and television industry by the issuance of bonds, loans, and setting up special funds. Introducing preferential and supportive policies is constructive to encourage and support the development of the film and television industry. The government could set up a special fund to 
support loans and export incentives for film and television companies. Moreover, the government could allocate the funds to subsidize film and television companies, which is conducive to the development of film and TV drama exports. The financial measures of the government, such as export tax rebates and subsidies, could effectively promote Chinese film and TV drama exports.

\subsection{Expand the film and television industry chain}

The film and television industry is a high-risk and high-investment industry. In addition to production, marketing and distribution, the complete value chain also includes the development of derivatives. After the screening of film and TV drama, filmmakers could develop derivatives of the value chain, including toy, game, animation, tourism, clothing and other products. Nowadays, the source of income for Chinese film and TV drama is relatively simple compared with Hollywood film accounting for $30 \%$ of total revenue, and the rest comes from derivatives. Therefore, Chinese companies should accelerate the development of the film and television industry chain. In the development of the industrial chain, copyright protection deserves attention, while Chinese film and television companies have not paid enough attention to it. The legitimate derivatives are only sold in cinemas, while the fake derivatives flood the market, which hinders the development of the film and TV drama derivatives. Hence film and television companies should expand the industry chain and pay attention to derivatives copyright protection.

\subsection{Strengthen international cooperation}

With the intensification of international competition, China should vigorously develop the film and television industry, which will affect China's economic status in the world. Through strategic cooperation, China could avoid obstacles in international trade. Co-production is the main way of international cooperation, which can be shared human, material and financial resources. By reducing the production and distribution costs of the film and TV drama, the international exchange can be promoted with win-win cooperation. Therefore, the government could establish a market-oriented financing system. Expanding financing channels is an effective way to solve the shortage of funds for Chinese film and television companies. Besides that, mainland China should strengthen cooperation with film and television companies in Hong Kong and Taiwan to achieve a good reputation and brand effect in the global market. So, China should build a multi-level, multi-channel integrated film and television market system. China could spread traditional Chinese culture through film and TV drama export.

\section{Conclusion}

In 2018, China surpassed North America to become the world's largest film market. The visual effects of Chinese films satisfy the psychological needs of the audience to obtain higher box office income. In addition to digital technology, the Chinese film and television industry should develop the value chain of film and television. The export of Chinese film and TV drama will be increased through derivatives to convey Chinese stories. China is gradually changing from an importer to an exporter of film and TV drama.

\section{References}

1. Hu, Y. (2016). On the Success of Korean Film and Television Culture Trade and Its Enlightenment to China. Economic Research Guide, 22, 164-165. DOI: 10.3969/j.issn.1673-291X.2016.22.073

2. Li, H. L. (2012). The International Route of Global Cultural Trade and the Development of Chinese Cultural Industry. China Business Update, 05, 48-50. DOI: 10.3969/j.issn.1009-9972.2007.05.017

3. Qian, Z. Z. (2008). The Dynamic Evolution of the Value Chain and the Continuous Competitive Advantage of the American Film Industry. Forum of World Economy Politics, 06, 106-111. DOI: 10.3969/j.issn.1007-1369.2008.06.017

4. Sun, Q. (2016). Analysis of the Current Situation and Restrictive Factors of Export Trade of Chinese Film and Television Culture. Modern Business, 25, 59-60. DOI: $10.3969 /$ j.issn.1673-5889.2016.25.027

5. Sun, Q. (2016). The Successful Mechanism of Korean Film and Television Cultural Trade and Its Enlightenment to China. China Economist, 08, 98-99. DOI: 10.3969/j.issn.1004-4914.2016.08.042

6. Wan, S. Y. (2017). Analysis of the Current Situation and Countermeasures of China's Cultural Trade. China International Business, 17, 20-21. DOI: 10.19516/j.cnki.10-1438/f.2017.17.009

7. Wang, S. J., Zhou, B., Bao, W., \& Liu, Z. Y. (2011). Research on Film and Television Cultural Creative Industry Chain and Its Technical Path. Journal of Kunming University of Science and Technology (Social Science), 02, 74-79. DOI: 10.16112/j.cnki.53-1160/c.2011.02.004 